\title{
28 Research Square \\ Phylogenetic Analysis of Kobuvirus and Astrovirus From Korean Wild Boars: 2016-2018
}

Jihye Shin

QIA: Animal and Plant Quarantine Agency

\section{SeEun Choe}

Animal and Plant Quarantine Agency

\section{Bang-Hun Hyun}

Animal and Plant Quarantine Agency

Dong-Jun An ( $\nabla$ andjun1202@gmail.com )

Animal and Plant Quarantine Agency https://orcid.org/0000-0002-5690-4039

\section{Research Article}

Keywords: porcine kobuvirus, porcine astrovirus, wild boar, phylogenetic tree

Posted Date: March 30th, 2021

DOI: https://doi.org/10.21203/rs.3.rs-337498/v1

License: @ (i) This work is licensed under a Creative Commons Attribution 4.0 International License.

Read Full License

Version of Record: A version of this preprint was published at Archives of Virology on July 9th, 2021. See the published version at https://doi.org/10.1007/s00705-021-05164-1. 


\section{Abstract}

The prevalence of porcine kobuvirus (PKoV) and porcine astrovirus (PAstV) in 845 Korean wild boars (KWB) during 2016-2018 were $28.0 \%$ and $10.6 \%$, respectively, and co-infection of two viruses showed $5.1 \%$. Phylogenetic tree analysis also revealed that 236 PKoVs from KWB were divided to diverse lineages within Aichivirus $C$ group but the one strain (WKoV16CN-8627) was included the same cluster with bovine kobuvirus (Achivirus B). Eighty-nine PAstVs from KWB was belonged predominantly to lineage PAstV4 and only one strain (WAst17JN-10931) included novel to lineage PAstV2. Two viruses are epidemic more in young ( $\leq 12$ months) than in old pigs (> 12 months).

\section{Introduction}

The genus Kobuviruses are small, non-enveloped viruses with single-stranded, positive-sense genomic RNA within the family Picornaviridae, genus Kobuvirus. The kobuvirus genome is approximately 8.2-8.4 $\mathrm{kb}$ in length, and its polyprotein includes non-structural leader (L) protein, three structural (VP0, VP3, and VP1) capsid proteins, and seven non-structural (2A-C, 3A-D) proteins [1, 2]. The genus kobuvirus consists of three species which were officially recognized as Aichivirus $A$ (Aichi virus) [3], Aichivirus $B$ (Bovine kobuvirus, BKoV) [4], and Aichivirus $C$ (Porcine kobuvirus, PKoV) [5]. PKoV was first identified in farm pigs in 2008 and named as S-1-HUN strains [1]. Since then, PKoV has been detected in fecal samples of healthy and diarrhoeic pigs in diverse countries including Japan [6], China [7], Thailand [8], South Korea [9], Italy [10], and USA [11]. Aichivirus has been reported one of the causative pathogens of human gastroenteritis, as biological properties have been reported through cell culture system [3]. Although the pathogenicity associated with diarrhea in PKoV has not clearly determined, it is considered important that PKoV may have possibility of zoonotic transmission among other species [12].

The genus Astroviruses are small non-enveloped RNA viruses with single-stranded, positive-sense genomic RNA from family Astroviridae, genus Mamastrovirus. The astrovirus genome is approximately 6.1-7.9 $\mathrm{kb}$ in length, and its polyprotein includes three open reading frames (ORFs) with ORF1a and ORF1b encoding non-structural proteins and ORF2 encoding structural capsid proteins [13]. Porcine astroviruses (PAstV) was first detected by electron microscopy in feces of diarrheic piglets in 1980 and was isolated later in cell culture [14]. Until recently, PAstV has been detected in feces of domestic pigs worldwide, including Hungary [15], Slovakia [16], Canada [17], Thailand [18], China [19], and South Korea [20]; it was classified into five genetic variable lineages, PAstV-1 to PAstV-5.

As the population density of the wild boar (Sus scrofa) increases in worldwide, there are concerned that wild boar potentially causes risk of transmission of infectious pathogens which can be shared with domestic pigs and other animal species [21]. It was also reported that wild boar in Asia and Europe may act as a reservoir for economic livestock diseases such as classical swine fever virus (CSFV), african swine fever virus (ASFV), porcine parvovirus (PPV), porcine reproductive and respiratory syndrome (PRRS), hepatitis E virus (HEV), and others [22]. In this study, we determined the circulation of PKoV and PAstV infecting wild boars in the South Korea, and investigated the prevalent levels and genetic diversity. 
The 729 of 845 wild boars captured by hunters for three years (2016-2018) were broadly ranged between $6 \mathrm{~kg}$ and $300 \mathrm{~kg}$. The age of wild boars was estimated based on weight: individuals were considered as young wild boar ( $\leq 2$ months, 3-6 months, 7-12 months) and adult wild boar (> 1 year). However, 116 of 845 wild boars without information were marked as unknown. All of captured wild boar fecal samples was no diarrhea and were collected from wild boar hunted randomly in the mountainous area in 9 provinces nationwide: Gyeonggi $(n=75)$, Gangwon $(n=112)$, Chungbuk $(n=111)$, Chungnam $(n=112)$, Jeonbuk $(n=82)$, Jeonnam $(n=88)$, Gyeongbuk $(n=167)$, Gyeongnam $(n=83)$, and Jeju $(n=15)$.

The fecal samples were resuspended in 10 volume of phosphate-buffered saline (PBS) containing $1 \%$ gentamicin (Gibco Life Technologies, Paisley, UK), and centrifuged to obtain clarified supernatant (at $5,000 \times \mathrm{g}$ for $10 \mathrm{~min})$. Viral RNA was extracted from the part of fecal supernatant $(0.2 \mathrm{ml})$ using a RNeasy Mini kit (QIAGEN, Valencia, CA, USA) and then reverse-transcribed into viral cDNA with a random hexanucleotide primers (NanoHelix, Daejeon, Korea). To detect enteric viruses (PKoV and PAstV) reverse transcription-polymerase chain reaction (RT-PCR) was carried out using primers conserved in 3D (RNAdependent RNA polymerase, RdRp) of PKoV and RdRp-ORF2 region of PAstV in previous studies, respectively $[9,20]$. The amplified genes were sequenced with specific primers using an ABI Prism 3730xi DNA Sequencer (Applied Biosystems, Foster City, CA, USA) at the CosmoGenetech (CosmoGenetech co., Daejeon, Korea). Each sequence was aligned and determined with references sequences which is deposited in GenBank using Clustal X 1.83 software [23]. The phylogenetic trees for PKoV and PAstV were constructed by Mega 6.0 software [24] using neighbor-joining method [25] and Kimura 2-parameter as genetic distance measure.

PKoV-positives were $28.0 \%$ (237/845) including unknown samples for wild boar age information and the prevalence rates according to age showed $33.8 \%(89 / 263)$ in young pigs ( $\leq 12$ months) and $26.2 \%$ (122/466) in old pigs (>12 months) $(22.4-30.4,95 \% \mathrm{Cl}$; confidence interval associated with the prevalence estimate) (Table 1). PAstV-positives were 10.6\% (90/845) including unknown samples for wild boar age and the prevalence rates according to age were also $16.7 \%(44 / 263)$ in young pigs ( $\leq 12$ months) and 9.2\% (43/466) in old pigs (> 12 months) $(6.9-12.2,95 \% \mathrm{Cl})$ (Table 1). Co-infection with PKoV and PAstV detected $5.1 \%$ (43/845) from individual wild boar fecal samples including unknown age samples. The coinfection of wild boars showed $4.1 \%(3 / 74)$ in 3-6 months, $9.9 \%(18 / 181)$ in $7-12$ months, and $4.3 \%$ (20/466) in > 12 months $(2.8-6.6,95 \% \mathrm{Cl})($ Table 1$)$.

In terms of geographical prevalence, PKoV and PAstV were broadly detected in most of provinces except that PAstV had not detected in Jeju island (Fig. 1A). The prevalence of PKoV in Gyeongnam $(42.2 \%$, 35/83) was significantly higher than that in Jeju island where shows lowest PKoV-infecting rate (13.3\%, $2 / 15)(p<0.05)$ (Fig. 1A). The recent prevalence of PKoV-infected wild boar was increased to $35.1 \%$ in 2018, compared with last years (18.7\% in 2016 and 24\% in 2017) (Fig. 1B). PAstV was detected in Gyeongbuk as highest PAstV-occurred region (19.2\%, 32/167), whereas had not detected in Jeju island (Fig. 1A). Emerging of PAstV in Korean wild boar has been firstly reported in 2011, however its prevalent levels were only $0.7 \%$ (1/146) wild boars [11]. Recently, between 2016-2018, wild boar PAstV tends to increase in Korea (3.2\% in 2016, 8.0\% in 2017, 15.9\% in 2018) (Fig. 1B). These findings indicate that 
enteric viruses, PKoV and PAstV are currently being transmitted in wild boar population, which consistently increase in the South Korea. In order to clarify whether the increase of virus-infected wild boars is affected epidemic circulation related to domestic pigs, additional investigation for PKoV and PAstV in farm pigs also may be required in future.

To investigate the genetic relationships among other Kobuvirus sequences, we constructed a phylogenetic tree for the 237 partial 3D gene of wild boar isolated in Korea (Fig. 2B). On the neighborjoining tree, the 236 Korean wild boar PKoV strains were divided the diversity lineages within Aichivirus $C$ (PKoV) group. Most of Korean wild boar PKoVs were belonged with domestic pig strains of many of countries: US, Japan, Thailand, China, Korea, Spain, and Hungary. Two of Korean wild boar strains (WKoV17GN-11321 and WKoV18GN-11819) were closed with WB-1-HUN2 strain isolated from Hungarian wild boar [26] (Fig. 2B).

We speculate that great spatial mobility of wild boar causes geographical circulation and genetical diverse of Korean PKoV. In comparison of the partial 3D nucleotides sequences, almost PKoV strains detected in Korean wild boars excepting one strain (WKoV16CN-8627) have high sequences identities indicating 83.5-94.5\% with Korean domestic pigs and 84.6-99.7\% with reference PKoV strains reported in Hungary [27], Spain, USA, China [2, 28, 29], Japan, and Thailand [30]. Interestingly, another wild boar PKoV strain, WKoV16CN-8627 showed low sequence identities ranging 50.2-54.9\% with Korean domestic pigs, whereas shared relatively higher identity levels as $74.2-75.7 \%$ with those of bovine kobuvirus (BKoV) strains (EGY-1 and U-1) $[4,31]$. This finding suggests that interspecies transmission between pigs and cow kobuviruses may have occurred in nature.

Phylogenetic tree shown that 90 wild boar PAstV strains were classified into different two lineages, PAstV2 and PAstV-4. The lineages PAstV-4 was dominantly identified in 89 of boars, followed by lineages PAstV-2 in only one of boar (strain WAst17JN-10931) (Fig. 2A). The PAstV isolated from wild boars has previously reported in several countries including Hungary [32], Slovakia [33], and Korea [20]. Especially, PAstVs isolated in Slovakia have been typed genetic variable lineages involved in PAstV-2, PAstV-4, and AstVs derived from different species (Chicken and bat) [33]. Whereas, Korean wild boar PAstV isolated in 2013 was limited in strain typed into PAstV-4 lineage [20]. In PAstV-4 lineage, three Korean wild boar PAstV strains (WAst18GB-11875, and WAst18JB-11889) were included with wild boar PAstV-4 (WBAstV-1 strain) in Hungary [32], and other four Korean wild boar PAstV strains (WAst17GG-10149, WAst17GB10880, WAst18GB-11497, and WAst18JB-11455) were also belonged with PAstK-31 strain detected from Korean wild boar in 2011 [20]. Other PAstV-4 strains of Korean wild boar were belonged in PAstV-4 lineage that clustered with those of domestic pigs in Hungary [26], Belgium, USA, China, and Korea [20]. Interestingly, WAst17JN-10931 strain was identified first time in PAstV-2 lineage which had not found in Korean wild boars (Fig. 2A). Korean AstV-2 sequences previously detected in domestic pigs in South Korea (PAstK-76 and KNH14-07) [20,34] may be closely related to wild boar PAstV-2 identified in this study. 
In conclusion, PKoV and PAstV in Korean wild boars are circulating nationwide regardless of the provinces and age. PKoV, WKoV16CN-8627 strain from Korean wild boar, showed relatively higher identity with those of bovine kobuvirus strain. It has shown the possibility of transmission between pigs and cattle kobuviruses in nature. We also suggest that PAstV-2 infecting Korean wild boar could be involved in the interspecies transmission of domestic pig astrovirus.

\section{Declarations}

\section{Acknowledgments}

This research was supported by grant (Project Code no. B-1543083-2019-21-02) from the Animal and Plant Quarantine Agency (APQA) and Ministry of Agriculture Food and Rural affairs (MAFRA), Republic of Korea.

\section{Data availability statement}

The partial 3D gene (488 bp) sequences of 135 PKoV strains (Accession number: MW297847MW297981) and the partial RdRp-ORF2 gene (799 bp) of 48 PAstV strains (Accession number: MW297982-MW298009, MW298011-MW298014, MW298018-MW298019, MW298023, MW298027, MW298034, MW298039-MW298041, MW298044, MW298047, MW298049-MW298053, and MW298056) detected from Korean wild boars have been deposited in GenBank.

\section{Compliance with ethical standards}

Conflict of interest The authors declare that they had no conflict of interest.

Ethical statement All animal experiments were approved by the Animal and Plant Quarantine Agency in Ministry of Agriculture Food and Rural affairs.

\section{References}

1. Reuter G, Boldizsar A, Pankovics P (2009). Complete nucleotide and amino acid sequences and genetic organization of porcine kobuvirus, a member of a new species in the genus Kobuvirus, family Picornaviridae. Arch Virol 154:101-108.

2. Yu JM, Xu Z Q, Li BW, Zhang Q, Cui SX, Jin M, Duan ZJ (2011). Analysis and characterization of the complete genome of a member of a new species of kobuvirus associated with swine. Arch Virol 156:747-751.

3. Yamashita T, Kobayashi S, Sakae K, Nakata S, Chiba S, Ishihara Y, Isomura S (1991). Isolation of cytopathic small round viruses with BS-C-1 cells from patients with gastroenteritis. J Infect Dis 164:954-957.

4. Yamashita T, Ito M, Kabashima Y, Tsuzuki H, Fujiura A, Sakae K (2003). Isolation and characterization of a new species of kobuvirus associated with cattle. J Gen Virol 84:3069-3077. 
5. Reuter G, Boldizsar A, Kiss I, Pankovics P (2008). Candidate new species of Kobuvirus in porcine hosts. Emerg Infect Dis 14:1968-1970.

6. Khamrin P, Maneekarn N, Hidaka S, Kishikawa S, Ushijima K, Okitsu S, Ushijima H (2010). Molecular detection of kobuvirus sequences in stool samples collected from healthy pigs in Japan. Infect Genet Evol 10:950-954.

7. Wang C, Lan D, Hua X (2011). Porcine kobuvirus from pig stool specimens in Shanghai, China. Virus Genes 43:350-352.

8. Khamrin P, Maneekarn N, Kongkaew A, Kongkaew S, Okitsu S, Ushijima H (2009). Porcine kobuvirus in piglets, Thailand. Emerg Infect Dis 15:2075-2076.

9. An DJ, Jeoung HY, Jeong W, Lee HS, Park JY, Kim B (2011). Porcine kobuvirus from pig stool in Korea. Virus Genes 42:208-211.

10. Di Profio F, Ceci C, Di Felice E, Marsilio F, Di Martino B (2013). Molecular detection of porcine kobuviruses in Italian swine. Res Vet Sci 95:782-785.

11. Verma H, Mor SK, Abdel-Glil MY, Goya SM (2013). Identification and molecular characterization of porcine kobuvirus in US swine. Virus Genes 46:551-553.

12. Chen L, Zhu L, Zhou Y, Xu Z, Guo W, Yang W (2013). Molecular and phylogenetic analysis of the porcine kobuvirus VP1 region using infected pigs from Sichuan Province, China. Virol J 10:281.

13. Matsui SM, Kiang D, Ginzton N, Chew T, Geigenmuller-Gnirke U (2001). Molecular biology of astroviruses: selected highlights. Novartis Found Symp 238:219-233.

14. Shimizu M, Shirai J, Narita M, Yamane T (1990). Cytopathic astrovirus isolated from porcine acute gastroenteritis in an established cell line derived from porcine embryonic kidney. J Clin Microbiol 28:201-206.

15. Reuter G, Pankovics P, Boros A (2011). Identification of a novel astrovirus in a domestic pig in Hungary. Arch Virol 156:125-128.

16. Salamunova S, Jackova A, Mandelik R, Novotny J, Vlasakova M, Vilcek S (2018). Molecular detection of enteric viruses and the genetic characterization of porcine astroviruses and sapoviruses in domestic pigs from Slovakian farms. BMC Vet Res 14:313.

17. Luo Z, Roi S, Dastor M, Gallice E, Laurin MA, L'homme Y (2011). Multiple novel and prevalent astroviruses in pigs. Vet Microbiol 149:316-323.

18. Kumthip K, Khamrin P, Saikruang W, Kongkaew A, Vachirachewin R, Ushijima H, Maneekarn N (2018). Detection and genetic characterization of porcine astroviruses in piglets with and without diarrhea in Thailand. Arch Virol 163:1823-1829.

19. Li JS, Li MZ, Zheng LS, Liu N, Li DD, Duan ZJ (2015). Identification and genetic characterization of two porcine astroviruses from domestic piglets in China. Arch Virol 160:3079-3084.

20. Lee MH, Jeoung HY, Park HR, Lim JA, Song JY, An DJ (2013). Phylogenetic analysis of porcine astrovirus in domestic pigs and wild boars in South Korea. Virus Genes 46:175-181. 
21. Miller RS, Sweeney SJ, Slootmaker C, Grear DA, Di Salvo PP, Kiser D, Shwiff SA (2017). Cross-species transmission potential between wild pigs, livestock, poultry, wildlife, and humans: implications for disease risk management in North America. Sci Rep 7:7821.

22. Meng XJ, Lindsay DS, Sriranganathan N (2009). Wild boars as sources for infectious diseases in livestock and humans. Philos Trans R Soc Lond B Biol Sci 364:2697-2707.

23. Thompson JD, Gibson TJ, Plewniak F, Jeanmougin F, Higgins DG (1997). The CLUSTAL_X windows interface: flexible strategies for multiple sequence alignment aided by quality analysis tools. Nucleic Acids Res 25:4876-4882.

24. Tamura K, Stecher G, Peterson D, Filipski A, Kumar S (2013). MEGA6: molecular evolutionary genetics analysis version 6.0. Mol Biol Evol 30:2725-2729.

25. Saitou N, Nei M (1987). The neighbor-joining method: a new method for reconstructing phylogenetic trees. Mol Biol Evol 4:406-425.

26. Reuter G, Kecskemeti S, Pankovics P (2010). Evolution of porcine kobuvirus infection, Hungary. Emerg Infect Dis 16:696-698.

27. Reuter G, Nemes C, Boros A, Kapusinszky B, Delwart E, Pankovics P (2013). Porcine kobuvirus in wild boars (Sus scrofa). Arch Virol 158:281-282.

28. Cao W, Zheng H, Zhang K, Jin Y, Lv L, Yang F, Liu X (2012). Complete genome sequence of the porcine kobuvirus variant $\mathrm{CH} / \mathrm{HNXX}-4 / 2012$. J Virol 86:11947.

29. Fan S, Sun H, Ying Y, Gao X, Wang Z, Yu Y, Li Y, Wang T, Yu Z, Yang S, Zhao Y, Qin C, Gao Y, Xia X (2013). Identification and characterization of porcine kobuvirus variant isolated from suckling piglet in Gansu province, China. Viruses 5:2548-2560.

30. Chuchaona W, Khamrin P, Yodmeeklin A, Kongkaew A, Vachirachewin R, Kumthip K, Ushijima H, Maneekarn N (2017). Detection and molecular characterization of porcine kobuvirus in piglets in 2009-2013 in northern Thailand. Trop Anim Health Prod 49:1077-1080.

31. Mohamed FF, Mansour SMG, Orabi A, El-Araby IE, Ng TFF, Mor SK, Goyal SM (2018). Detection and genetic characterization of bovine kobuvirus from calves in Egypt. Arch Virol 163:1439-1447.

32. Reuter G, Nemes C, Boros A, Kapusinszky B, Delwart E, Pankovics P (2012). Astrovirus in wild boars (Sus scrofa) in Hungary. Arch Virol 157:1143-1147.

33. Vilcek S, Salamunova S, Jackova A (2019). Genetic identification of astroviruses in wild boars. J Vet Sci 20:91-94.

34. Lee S, Jang G, Lee C (2015). Complete genome sequence of a porcine astrovirus from South Korea. Arch Virol 160:1819-1821.

\section{Table}

Table 1. Prevalence of porcine kobuvirus (PKoV) and astrovairus (PAstV) in different age groups of wild boars. 


\begin{tabular}{|c|c|c|c|c|c|c|c|}
\hline \multirow[t]{2}{*}{$\begin{array}{l}\text { Wild } \\
\text { boar }\end{array}$} & \multirow[t]{2}{*}{ Age } & \multicolumn{2}{|l|}{ PKoV } & \multicolumn{2}{|l|}{ PAstV } & \multicolumn{2}{|l|}{$\begin{array}{l}\text { Co-infection } \\
\text { (PKoV+PAstV) }\end{array}$} \\
\hline & & $\begin{array}{l}\text { Positive } \\
\text { percentage (\%) }\end{array}$ & $\begin{array}{l}95 \% \\
\mathrm{Cl}^{\mathrm{a}}\end{array}$ & $\begin{array}{l}\text { Positive } \\
\text { percentage (\%) }\end{array}$ & $\begin{array}{l}95 \% \\
\mathrm{Cl}\end{array}$ & $\begin{array}{l}\text { Positive } \\
\text { percentage (\%) }\end{array}$ & $\begin{array}{l}95 \% \\
\mathrm{Cl}\end{array}$ \\
\hline & $\begin{array}{l}\leq 2 \\
\mathrm{~m}^{\mathrm{b}}\end{array}$ & $50.0^{c}(4 / 8)^{d}$ & $\begin{array}{l}21.5- \\
78.5\end{array}$ & $0(0 / 8)$ & $\begin{array}{l}0- \\
29.3\end{array}$ & $0(0 / 8)$ & $\begin{array}{l}0- \\
29.3\end{array}$ \\
\hline \multirow[t]{2}{*}{ Young } & $\begin{array}{l}3-6 \\
m\end{array}$ & $33.8(25 / 74)$ & $\begin{array}{l}24.0- \\
45.2\end{array}$ & $14.9(11 / 74)$ & $\begin{array}{l}8.3- \\
24.9\end{array}$ & $4.1(3 / 74)$ & $\begin{array}{l}0.9- \\
11.7\end{array}$ \\
\hline & $\begin{array}{l}7- \\
12 \\
\mathrm{~m}\end{array}$ & $33.1(60 / 181)$ & $\begin{array}{l}26.7- \\
40.3\end{array}$ & $18.2(33 / 181)$ & $\begin{array}{l}13.3- \\
24.5\end{array}$ & $9.9(18 / 181)$ & $\begin{array}{l}13.3- \\
24.5\end{array}$ \\
\hline Adult & $\begin{array}{l}> \\
12 \\
\mathrm{~m}\end{array}$ & $26.2(122 / 466)$ & $\begin{array}{l}22.4- \\
30.4\end{array}$ & $9.2(43 / 466)$ & $\begin{array}{l}6.9- \\
12.2\end{array}$ & $4.3(20 / 466)$ & $\begin{array}{l}2.8- \\
6.6\end{array}$ \\
\hline Unknown & & $22.4(26 / 116)$ & $\begin{array}{l}15.7- \\
30.9\end{array}$ & $2.6(3 / 116)$ & $\begin{array}{l}0.6- \\
7.7\end{array}$ & $1.7(2 / 116)$ & $\begin{array}{l}0.1- \\
6.5\end{array}$ \\
\hline
\end{tabular}

a, Cl: Confidence interval associated with the prevalence estimate

b, m: month

c: positive percent

d: (number of positive/ number of test samples).

\section{Figures}



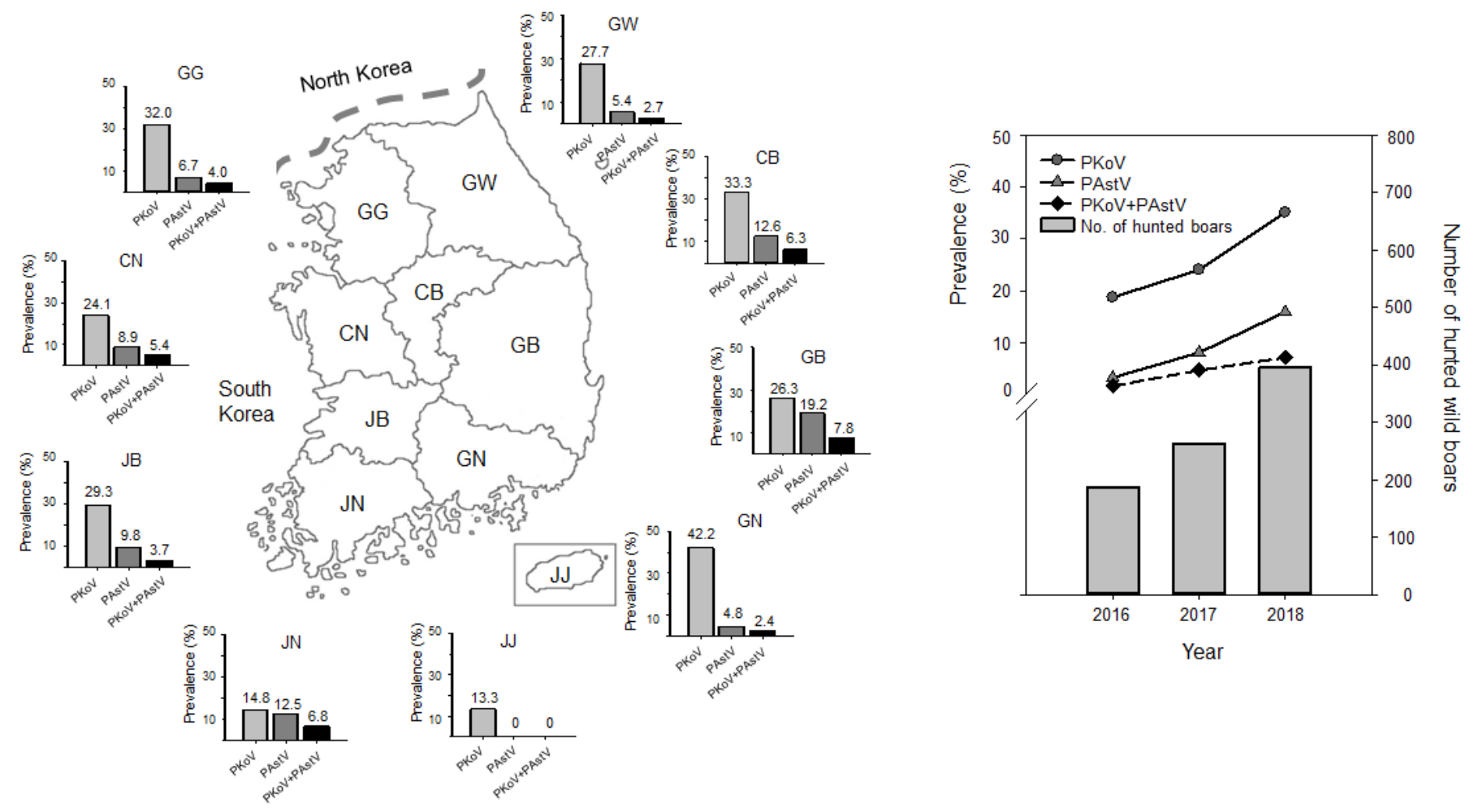

\section{Figure 1}

Prevalence of PKoV and PAstV in Korean wild boar. Geographic distribution of wild boar confirmed as PKoV- or PAstV-positive in South Korea (A). Each percentage according to year indicates frequency of virus infecting wild boar with regard to PKoV and PAstV (B). Gyeonggi (GG), Gangwon (GW), Chungbuk (CB), Chungnam (CN), Jeonbuk (JB), Jeonnam (JN), Gyeongbuk (GB), Gyeongnam (GN), and Jeju (JJ). Note: The designations employed and the presentation of the material on this map do not imply the expression of any opinion whatsoever on the part of Research Square concerning the legal status of any country, territory, city or area or of its authorities, or concerning the delimitation of its frontiers or boundaries. This map has been provided by the authors. 
(B)
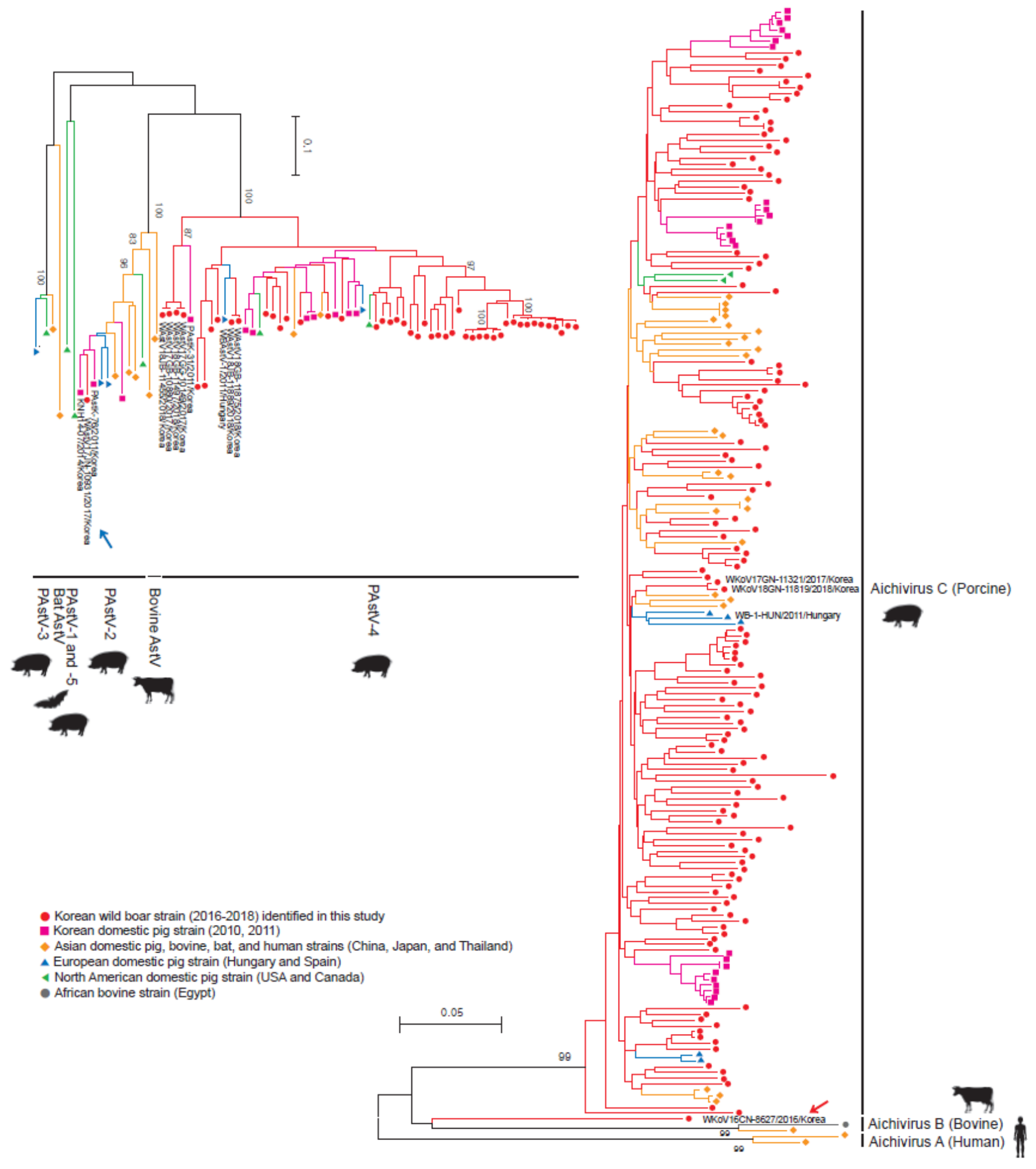

(8)

\section{Figure 2}

Phylogenetic tree analysis based on the partial RdRp-ORF2 gene (799 bp) of astrovirus (AstV) strains and the partial 3D gene (488 bp) of kobuvirus (KoV) strains. The partial RdRp-ORF2 sequences of 48 PAstV isolated from wild boar were compared with 22 global AstV strains available in GenBank database (A). The partial 3D sequences of $135 \mathrm{KoV}$ isolated from wild boar were compared with 66 global KoV strains available in GenBank database (B). The trees were constructed using the neighbor-joining method (MEGA 
v6.0) with bootstrap values calculated from 1,000 replicates. The PKoV (WKoV16CN-8627 strain) and PAstV (WAst17JN-10931 strain) from Korean wild boars are marked red and blue arrows, respectively. 